4 Macpherson R, Butler J. Effect of treatment in an active rehabilitation hostel on the need for hospital treatment. Psychiatr Bull 1999; 23: 594-7.

5 Simpson S, Middleton N. Fast stream psychiatric rehabilitation after recent hospital closure. Psychiatr Bull 1994; 18: 613-4.

6 Killaspy H, Rambarran D, Bledin K. Mental health needs of clients of rehabilitation services: a survey in one trust. J Ment Health 2008; 17: 207-18.

7 Office of National Statistics. Population and Vital Statistics by Area of Usual Residence in the United Kingdom, 2006. ONS, 2008.

8 Lelliott $\mathrm{P}$, Audini B, Knapp M, Chisholm D. The mental health residential care study: classification of facilities and description of residents. $\mathrm{Br}$ Psychiatry 1996; 169: 139-47.

9 Connolly M, Kelly C. Lifestyle and physical health in schizophrenia. Adv Psychiatr Treat 2005; 11: 125-32.
10 Commander M, Rooprai D. Survey of long-stay patients on acute psychiatric wards. Psychiatr Bull 2008; 32: 380-3.

11 Mountain D, Killaspy $H$, Holloway F. Mental health rehabilitation services in the UK in 2007. Psychiatr Bull 2009; 33: 215-8.

12 Macpherson R, Shepherd G, Edwards T. Supported accommodation for people with severe mental illness: a review. Adv Psychiatr Treat 2004; 10: $180-8$.

13 Ryan T, Hatfield B, Sharma I, Simpson V, Mclntyre A. A census study of independent mental health sector usage across seven strategic health authorities. J Ment Health 2007; 16: 243-53.

14 Royal College of Psychiatrists, Mental Health Network, NHS Confederation and London School of Economics and Political Science. Mental Health and the Economic Downturn: National Priorities and NHS Solutions (Occasional Paper OP70). Royal College of Psychiatrists, 2009 (http://www.rcpsych.ac.uk/files/pdfversion/OP70.pdf).

\title{
Psychiatrists' experiences of stalking in Ireland: prevalence and characteristics
}

\author{
Izu Nwachukwu, ${ }^{1}$ Vincent Agyapong, ${ }^{2}$ Leah Quinlivan, ${ }^{1}$ John Tobin, ${ }^{3}$ Kevin Malone ${ }^{1}$
}

The Psychiatrist (2012), 36, 89-93, doi: 10.1192/pb.bp.111.034660

${ }^{1}$ University College Dublin; ${ }^{2}$ St Patrick's Hospital \& University of Dublin (Trinity College) Dublin; ${ }^{3}$ St Bricin's Hospital, Dublin, Ireland

Correspondence to Izu Nwachukwu (izunwachukwu@hotmail.com)

First received 20 Mar 2011, final revision 21 Nov 2011, accepted 28 Nov 2011
Aims and method Accumulating evidence suggest that psychiatrists may be at greater risk of being stalked compared with the general population. We used a selfadministered questionnaire to survey psychiatrists in Ireland about their experiences, practices and attitudes regarding work-related stalking.

Results We found that $25.1 \%$ of psychiatrists in Ireland had been the subject of stalking behaviour at some point in their career. At the time of the survey, $5.5 \%$ of respondents were actively being stalked. The majority of the stalking occurred in the workplace and most of the perpetrators were patients. Most of the victims were unaware of guidelines or other supportive mechanisms in their workplace. Of those who reported their experiences to authorities, almost half were not satisfied with the support they received.

Clinical implications Stalking of psychiatrists is not uncommon. Employers should put in place supportive structures backed up by education and training to reduce the incidence, associated morbidity and other wider consequences of stalking.

Declaration of interest None.
Since the 1990s, more attention has been paid to stalking and how it affects both victims and perpetrators. Enactment of the first anti-stalking legislation in California, USA, in 1990 and subsequent widespread criminalisation of stalking across other Western jurisdictions was quickly followed by increased media attention, research interest and clinical understanding of stalking and related behaviour patterns. Despite the accumulating body of knowledge, there remains considerable variation in what constitutes stalking from the clinical, research and legal perspectives. ${ }^{1}$

Stalking has been variously defined depending on the setting or context in which the behaviour is being assessed. Three key elements appear to be common to the majority of definitions found in literature. These elements include: (1) a pattern or course of behaviour that is directed at a person; (2) this behaviour is used to convey an implicit or explicit threat and/or is perceived by the target as unwanted and intrusive; and (3) an experience of fear or concern by the target. $^{2,3}$ As an example, Mullen and colleagues ${ }^{4}$ defined stalking as 'those repeated acts, experienced as unpleasantly intrusive, which create apprehension and can be understood by a reasonable fellow citizen (the ordinary man or woman) to be grounds for becoming fearful'.

In Ireland, stalking is covered by Section 10 of the NonFatal Offences against the Person Act that was enacted in 1997. As Irish society became aware of the legal protection against stalking, the incidents of recorded complaints to the police of stalking behaviour rose from 97 in 2000 to 759 in 2008. Notwithstanding this marked rise, the incidence of stalking in the general population is probably underreported.

Healthcare professionals are reported to have been stalked at rates higher than the general population. ${ }^{1}$ Mental 
health professionals are at a higher risk and have reported increased anxiety, stress, time off work and financial loss when they are subjected to this form of behaviour. ${ }^{5}$ In 2002, Sandberg and colleagues surveyed 62 members of staff from an urban in-patient clinic in the USA and found that $8 \%$ had been obsessionally followed by a patient. ${ }^{6}$ In an earlier study, Sandberg et al reported that patients who had stalked or harassed staff were significantly more likely to have a diagnosis of personality disorder and/or paranoid disorder and to have an earlier history of assault or fear-inducing behaviour. They were also more likely to be single and male, and to have a history of multiple hospitalisations, selfinjurious behaviours and substance misuse. ${ }^{7}$ A German study of psychiatrists, psychologists and psychotherapists reported that $38 \%$ of respondents had been victims of stalking behaviour. ${ }^{8}$ However, in an Italian study of all mental health professionals, $11 \%$ reported that they had been subjected to stalking behaviour. ${ }^{9}$

There are only a few studies globally that have looked at the experiences of psychiatrists alone as victims of stalking behaviour. In 2008, the Royal College of Psychiatrists in the UK surveyed its members on their experiences of being stalked. Overall, $21.3 \%$ of psychiatrists in the UK considered themselves to have experienced being stalked. ${ }^{10}$

Despite evidence indicating high levels of stalking behaviour targeted at mental health professionals, to our knowledge, there has been no study examining the prevalence of stalking and its effects among psychiatrists in Ireland. As such, this study sought to explore the experiences and attitudes of psychiatrists in Ireland towards work-related stalking. It also sought to investigate the availability and effectiveness of practice guidelines and support services in the workplace for psychiatrists in Ireland who become victims of stalking.

\section{Method}

A self-administered questionnaire that had multiple categorical variables was developed de novo by the authors, based on a literature review, to reflect the objectives of our study (available from the author on request). The questionnaire was pre-tested with ten psychiatrists not included in the study sample and took $10 \mathrm{~min}$ to complete. A definition of stalking (as per Mullen and colleagues as described earlier ${ }^{4}$ ) was provided to guide respondents on what could be reasonably described as stalking behaviours and experiences.

The questionnaires were posted out to all consultant psychiatrists and post-MRCPsych trainees on the register of the College of Psychiatry of Ireland in May 2009. Selfaddressed envelopes were included for return of completed surveys. Email reminders were used to optimise the response rate.

Ethical approval for this study was obtained from the ethics committee of St Vincent's University Hospital, Dublin. Consent was assumed to be implied once survey forms were completed and returned. Data were analysed anonymously using descriptive statistics with SPSS version 17 on Windows.

\section{Results}

\section{Incidence and typology of stalking}

A total of 442 questionnaires were posted and 274 completed forms were returned, giving a response rate of $62 \%$. Of the responders, $123(44.9 \%)$ were males and 151 (55.1\%) were females. Of these, 69 psychiatrists (25.1\%) considered themselves to have been victims of stalking at some point in their career, including $34(49.3 \%)$ males and $35(50.7 \%)$ females. In all, 15 psychiatrists $(5.5 \%)$ reported being actively stalked at the time of the survey. Table 1 illustrates the demographic profile of respondents who had experienced stalking.

Eleven psychiatrists reported that they had been stalked on more than one occasion by more than one individual. The highest number of experiences of stalking reported was 5 episodes by 1 psychiatrist, and in all, 95 different unconnected episodes of stalking behaviour were reported by the 274 respondents.

Of the stalkers, $88.4 \% \quad(n=84)$ were reported to be patients. The other stalkers were strangers in $5.2 \%(n=5)$ of cases and familiar people in $6.3 \%(n=6)$ of cases. These two groups probably reflect the incidence of being stalked by this cohort irrespective of their employment. Of the stalkers, $70.5 \%(n=67)$ were male and $28.4 \%$ were female $(n=27)$. There was only one incident where the gender of the stalker was unknown.

The majority of the stalking behaviour was experienced in the workplace, with a total of 42 respondents reporting such experiences. Twenty individuals reported experiencing stalking both at work and at home; ten reported being stalked only in the home environment, whereas only four reported being stalked on the streets. The most common form of stalking behaviour was unwanted telephone calls (40 incidences). This was followed by verbal or physical

\begin{tabular}{|c|c|c|}
\hline \multicolumn{3}{|c|}{$\begin{array}{l}\text { Table } 1 \text { Profile of psychiatrists }(n=69) \text { who had } \\
\text { experienced stalking }\end{array}$} \\
\hline Key variables & $\begin{array}{c}\text { Stalked } \\
n(\%) \\
(n=69)\end{array}$ & $\begin{array}{l}\% \text { of all } \\
\text { respondents } \\
(n=274)\end{array}$ \\
\hline \multicolumn{3}{|l|}{ Gender } \\
\hline Male & $34(49.3)$ & 12.4 \\
\hline Female & $35(50.7)$ & 12.8 \\
\hline \multicolumn{3}{|l|}{ Age, years } \\
\hline$<35$ & $7(10.1)$ & 2.6 \\
\hline $35-50$ & $29(42.0)$ & 10.6 \\
\hline$>50$ & $33(47.8)$ & 12.0 \\
\hline \multicolumn{3}{|l|}{ Position } \\
\hline Consultant & $58(84.1)$ & 21.2 \\
\hline Non-consultant & $11(15.9)$ & 4.1 \\
\hline \multicolumn{3}{|l|}{ Specialty } \\
\hline Adult & $45(65.2)$ & 16.4 \\
\hline Child and adolescent & $9(13.0)$ & 3.3 \\
\hline Forensic & $4(5.8)$ & 1.5 \\
\hline Addictions & $3(4.3)$ & 1.1 \\
\hline Others & $8(11.6)$ & 2.9 \\
\hline \multicolumn{3}{|c|}{ Principal location of clinical practice } \\
\hline Public & $55(79.7)$ & 20.1 \\
\hline Private & $9(13.0)$ & 3.3 \\
\hline Both & $5(7.2)$ & 1.8 \\
\hline
\end{tabular}


threats (30 incidences). Less common were: unwanted contact made by the stalker with the psychiatrist's family and friends (11 incidences); graffiti (8 incidences); unwanted gifts (8 incidences); and harassment through the internet (4 incidences). There were 11 reports of stalking by other means, 10 of which were by letters. No respondent had been physically attacked.

\section{Impact on the victims of stalking}

Of the respondents who reported having been stalked $(n=69), 85 \%(n=59)$ reported that they suffered psychological distress as a result of their experience. The experience of being stalked affected the work of $26.1 \%(n=18)$ and $24.6 \%(n=17)$ were affected in their social life. Of the total of 69 victims of stalking, $5.8 \%(n=4)$ considered resigning from their work as a result of their experiences. The stalking behaviour did not always affect the victim alone. In $34.7 \%$ $(n=24)$ of cases it affected the partner or spouse of the psychiatrist.

\section{Attitudes to reporting stalking experiences}

A total of $94 \%(n=65)$ reported their experience of being stalked to at least one other person. In total, $46.2 \%(n=30)$ of reports were to the employer; $35.4 \%(n=23)$ to the police and $18.5 \%(n=12)$ made complaints to both their employers and the police; $18.5 \%(n=12)$ reported to someone else who was neither their employer nor the police. Of all those who made a report of their experience, nearly half considered that they had not received appropriate support.

\section{Diagnosis of stalker}

Our questionnaire sought the professional opinions of the respondents as to the psychiatric diagnosis of their stalker when these where known to be patients. The most common primary diagnosis was personality disorder, with $33.3 \%$ $(n=28)$ of incidences, followed by psychotic disorders $(29.8 \%, n=25)$. Others were substance misuse - $10.7 \%$ $(n=9)$; and comorbid personality and substance misuse disorders - 10.7\% ( $n=9)$. Affective disorder and anxiety disorder were the primary diagnoses in $2.4 \%(n=2)$ and $1.2 \%(n=1)$ of cases respectively. A category of 'other diagnoses' applied to $11.9 \%(n=10)$ individuals.

\section{General knowledge and attitudes to being stalked}

Only $7.3 \%(n=20)$ of the respondents had awareness of any guidelines or policies in their workplace on stalking, and $13.9 \%(n=38)$ were aware of national laws against stalkingtype behaviours. The majority of respondents $(65.7 \%$, $n=180$ ) were aware of at least one colleague who had been a victim of stalking behaviour. There was a general sense of awareness that psychiatrists are at increased risk of being stalked, with $52 \%(n=143)$ describing themselves as 'well aware', $42 \%(n=116)$ 'just aware' and only $6 \%(n=16)$ as 'unaware'.

The level of awareness of respondents was reflected by various precautions taken to avoid being stalked. A total of $79 \%(n=217)$ of the respondents deliberately did not have their name in the telephone directory; $10.2 \%(n=28)$ did not have their name on the electoral register; $61 \%(n=169)$ did not have their home address on the Medical Council website. Only $1.5 \% \quad(n=4)$ of respondents frequently changed their telephone number; 61\% $(n=169)$ had their telephone number unavailable to others when they made calls and $42.7 \%(n=117)$ deliberately avoided using social network internet sites for fear of being stalked.

\section{Discussion}

Our finding of a prevalence rate of $25.1 \%$ is similar to that found by the Royal College of Psychiatrists in the UK where $21.3 \%$ of psychiatrists considered themselves to have experienced being stalked. ${ }^{10}$ These prevalence rates differ from the $11 \%$ reported in the Italian study ${ }^{11}$ and $38 \%$ reported in the German study. ${ }^{8}$ However, as the latter two studies were not limited to psychiatrists, any comparisons with the Irish study need to be viewed in that light. Also, differences in methodology and definitions of stalking may limit the comparability of results.

We found that a slightly higher proportion of male psychiatrists reported being victims of stalking behaviour compared with their female counterparts (28\% v. 23\%). In absolute terms however, more female psychiatrists reported being victims of stalking (51\%). This is consistent with a UK study of psychiatrists ${ }^{11}$ and nurses ${ }^{12}$ that found that more females (59\% and $78.6 \%$ respectively) had been victims of stalking behaviour.

When a psychiatrist becomes the victim of stalking by their patient, their capacity to form an objective opinion of the psychiatric diagnosis of the stalker may be influenced by their subjective experiences. Allowing for this caveat, we found that $88.4 \%$ of the stalkers in our study were patients compared with $71 \%$ in the College's study. ${ }^{10}$ In both groups the greatest risk was presented by patients with either a psychotic disorder or a personality disorder. Similarly, in the Italian study, ${ }^{9} 45 \%$ of the stalkers had a psychotic disorder; $11 \%$ had a mood disorder and $37 \%$ had a personality disorder, whereas in the German study, ${ }^{8} 41.9 \%$ of the stalkers had a delusional disorder.

In our study, $70.5 \%$ of stalking incidences were perpetrated by males in contrast with the findings in the College study ${ }^{10}$ and German study ${ }^{8}$ where $59 \%$ and $60 \%$ respectively of the stalkers were female. However, in another UK study that looked at stalking of nurses, ${ }^{12}$ $82.1 \%$ of the stalkers were males.

With regard to stalking behaviours, we found that unwanted telephone calls were the most common form. This is consistent with findings from the Italian study of mental health professionals ${ }^{9}$ that found that unwanted telephone calls $(75 \%)$ followed by loitering near the victim (58\%) were the most reported stalking behaviour.

There was a general lack of awareness of national laws that criminalise stalking. Very few respondents were aware of guidelines or policies available in their workplace on how to deal with this unwanted behaviour, probably reflecting a general unavailability of these guidelines in most workplaces. However, the majority of respondents had a good understanding that being a victim of stalking was an occupational hazard. Preventative behaviours were centred on making their telephone number and their home address unavailable to the public. 
Stalking of mental health professionals is done for a variety of reasons. The predominant motivation of stalkers formed one of the three axes along which Mullen and colleagues developed their famed typology of stalking in 1999. ${ }^{13}$ The other axes were the nature of the stalker's original relationship with their victim; and the stalker's psychiatric diagnosis. ${ }^{13}$ When psychiatrists are stalked it is almost always perpetrated by current or ex-patients who feel that they have been in some way wronged, misunderstood or mistreated. These particular stalkers are retaliating to a perceived injustice, and were classed as 'the resentful stalkers' in the scheme developed by Mullen et $a l^{13}$ Paranoid personalities and paranoid delusions are frequently found in resentful stalkers. There are other patients who do not understand the boundaries that are required for a professional relationship. This group can perceive kindness and compassion as indicating a deeper and more personal kind of relationship than exists. These stalkers fall between the 'intimacy seeking' and 'incompetent' types of stalkers. Their stalking behaviours are usually directed at achieving amorous relationships, but they can also react with anger when they perceive themselves as rejected. Erotomanic delusions are commonly found in intimacy-seeking stalkers and incompetent stalkers are frequently found to have impaired cognitive function. Mullen and colleagues also described 'the rejected stalkers' who are primarily driven by a desire to reunite with or exact revenge on a person with whom they were previously related. ${ }^{13}$ These individuals are frequently found to have personality disorders, particularly of the narcissistic and dependent types.

In our study, most stalking occurred in the workplace and a large number of respondents reported that it had a negative psychological impact on them. In the College study ${ }^{10}$ referred to earlier, $65 \%$ of those who had been stalked reported feeling significant anxiety or fear; $19 \%$ had difficulties sleeping; $11 \%$ lost a sense of joy from life; and $5 \%$ reported that they had symptoms consistent with mental illness. In response to this report the College established the Psychiatrists' Support Service for members who experienced stalking. ${ }^{10}$

Given that almost $85 \%$ of our respondents who had been stalked reported that they suffered psychological distress as a result of their experience, it is essential that support structures similar to what was put in place by the Royal College of Psychiatrists in the UK are considered in Ireland. Perhaps our finding that $5.5 \%$ of respondents were actively being stalked highlights the urgency required in instituting such a measure. It is also alarming that almost half of those who reported their experiences to authorities were not satisfied with the support they received. Adequate support structures should be established by the employing organisations backed up by education and training about stalking. Attention must also be paid to psychiatrists working in purely private capacities who probably have the least potential support. In this regard, postgraduate colleges and other professional bodies may have a role in highlighting this unmet need of their members to employers and other relevant authorities, albeit to minimise any potential impact on recruitment and retention of psychiatrists.

\section{Limitations}

This study may be limited by being observational in type and involving only one assessment over a limited period of time. It is probable that many of the 168 psychiatrists who did not respond to the survey had not had such an experience and therefore did not consider that stalking was a significant problem. Although this cannot be said with certainty, it remains relevant. With this in mind it would be appropriate to consider that the real prevalence of psychiatrists who have been the victim of stalking in Ireland is probably less than the $25.1 \%$ that we found in this study. The other side of this argument would be the possibility that some psychiatrists who had been victims of stalking might have resigned from their jobs, with the result that they would not have been available to be surveyed. Indeed, one respondent reported in free text that they knew of three colleagues who had resigned from their jobs following stalking experiences. There is also the possibility that some psychiatrists who had been (or were being) stalked could have been too distressed to respond to the survey. Another potential limitation is that, for reasons of brevity, this study was limited to a quantitative survey and so was unable to establish the finer characteristic details of the stalking experienced by our respondents. Future qualitative studies may need to be focused primarily on psychiatrists who have experienced stalking in order to provide such necessary level of detail.

\section{Implications}

Stalking of psychiatrists is not uncommon. The experience of psychiatrists in Ireland in regard to work-related stalking appears similar to that which exists elsewhere. The effects of stalking on psychiatrists include serious psychological distress and varying degrees of socio-occupational disruption. Given that most of these stalking experiences are work related, employers have a responsibility to provide mechanisms for educating and supporting psychiatrists, and indeed other mental health workers. It is hoped that as the clinical understanding of stalking and related behaviour patterns progressively improve, psychiatrists will become more aware of this potential occupational hazard, and will develop more effective approaches to reduce its incidence and manage its sequalae.

\section{Funding}

This study was supported by the Adult Faculty of the College of Psychiatrists of Ireland.

\section{Acknowledgements}

We thank Superintendent F.W. Healy, of the Crime Statistic Office, Crime Policy and Administration, Garda Headquarters, The Phoenix Park, Dublin 8 for providing us with the information on the incidents of stalking-related behaviours in Ireland. We also thank Dr Larkin Feeney for his help in editing the manuscript; and Ms Grace Smyth of the College of Psychiatry of Ireland for the administrative support she provided throughout this project.

\section{About the authors}

Dr Izu Nwachukwu is a senior registrar and lecturer in psychiatry, St Vincent's University Hospital, Department of Psychiatry \& Mental Health Research, School of Medicine \& Medical Sciences, University College 
Dublin. Dr Vincent Agyapong is a senior registrar and lecturer in psychiatry, St Patrick's Hospital and University of Dublin (Trinity College) Dublin. Leah Quinlivan is a PhD Research Fellow, Department of Psychiatry \& Mental Health Research, School of Medicine \& Medical Sciences, University College Dublin. Dr John Tobin is a consultant psychiatrist, St Bricin's Hospital, Dublin. Professor Kevin Malone is head of the Department of Psychiatry \& Mental Health Research, School of Medicine $\&$ Medical Sciences, University College Dublin, Ireland.

\section{References}

1 Giorgi-Guarnieri D, Norko MA. Stalking: introduction, definition and epidemiology. In Stalking - Psychiatric Perspectives and Practical Approaches (ed. DA Pinals): 3-6. Oxford University Press, 2007.

2 Meloy JR. The Psychology of Stalking: Clinical and Legal Perspectives. Academic Press, 1998.

3 Westrup D, Fremouw WJ. Stalking behaviour: a literature review and suggested functional analytic assessment technology. Aggress Violent Behav 1998; 3: 255-74

4 Mullen PE, Pathe M, Purcell R. Stalkers and their Victims (2nd edn). Cambridge University Press, 2008.

5 Romans JS, Hays JR, White TK. Stalking and related behaviours experienced by counselling centre staff members from current or former clients. Prof Psychol 1996; 27: 595-9.
6 Sandberg DA, McNeil DE, Binder RL. Stalking, threatening and harassing and harassing behaviour by psychiatric patients towards clinicians. J Am Acad Psychiatry Law 2002; 30: 221-9.

7 Sandberg DA, McNeil DA, Binder RL. Characteristics of psychiatric inpatients who stalk, threaten, or harass hospital staff after discharge. Am J Psychiatry 1998; 155: 1102-5.

8 Krammer A, Stepan A, Baranyi A, Kapfhammer HP, Rothenhäusler HB. The effects of stalking on psychiatrists, psychotherapists and psychologists. Prevalence of stalking and its emotional impact [in German]. Nervenarzt 2007; 78: 809-17.

9 Galeazzi GM, Elkins BA, Curci P. Emergency psychiatry: the stalking of mental health professionals by patients. Psychiatr Serv 2005; 56: 137-8.

10 Royal College of Psychiatrists. 1 in 10 psychiatrists are victims of stalking: 1 in 3 report harassment from stalking behaviours. Roya College of Psychiatrists, 2008 (http://www.rcpsych.ac.uk/press/ pressreleases2008/pr985.aspx).

11 Mclvor RJ, Potter L, Davies L. Stalking behaviour by patients towards psychiatrists in a large mental health organisation. Int J Soc Psychiatry 2008; 54: 350-7.

12 Ashmore R, Jones J, Jackson A, Smoyak S. A survey of mental health nurses experiencing stalking. J Psychiatr Ment Health Nurs 2006; 13 562-9.

13 Mullen PE, Pathe M, Purcell R, Stuart GW. Study of stalkers. Am J Psychiatry 1999; 156: 1244-9.

\title{
Assessing whether psychiatric trainees feel safe in the workplace
}

\author{
Catia Acosta, ${ }^{1}$ James Warner, ${ }^{2}$ Michael Kopelman, ${ }^{1}$ Ramin Nilforooshan ${ }^{3}$
}

The Psychiatrist (2012), 36, 93-96, doi: 10.1192/pb.bp.110.032987

${ }^{1}$ South London and Maudsley NHS Foundation Trust; ${ }^{2}$ Central and North West London NHS Foundation Trust; ${ }^{3}$ Surrey and Borders Partnership NHS Foundation Trust

Correspondence to Ramin

Nilforooshan

(ramin.nilforooshan@nhs.net)

First received 7 Oct 2010, final revision 24 Jul 2011, accepted 21 Sep 2011

\begin{abstract}
Aims and method Previous studies have shown that 17 to $60 \%$ of psychiatric trainees have been physically or verbally assaulted. To measure the frequency of assaults and the trainees' reactions, we conducted a retrospective self-reported survey of attendees at MRCPsych teaching courses in south London and at an annual meeting of psychiatric trainees.

Results Overall, $64 \%$ of the questionnaires distributed were returned completed. Of the trainees who responded, $41 \%$ had been physically assaulted at least once and $89 \%$ had been verbally assaulted. As a result of the assault, $34 \%$ of trainees were subsequently more risk aware and $11 \%$ were now hesitant to assess patients with a history of violence. There was no association between the level of training or attendance at a breakaway training course and having been subject to physical assault.
\end{abstract}

Clinical implications Our study showed unacceptable levels of physical and verbal assault on psychiatric trainees and an important effect of those incidents on clinical practice.

Declaration of interest None.
Previous studies have shown that many psychiatrists have been assaulted and/or threatened while at work, with prevalence ranging from 17 to $60 \% .^{1-5}$ Few studies on this subject have been undertaken in England. Davies noted that over the year, $17 \%$ of respondents reported one or more assaults (of those, $42 \%$ were assaulted more than once) and $32 \%$ reported one or more threats. ${ }^{1}$ Most of the assaults $(61 \%)$ were committed by patients in general adult 